\title{
ÁREAS DE SILÊNCIO E CORPO DIABÉTICO
}

\author{
SILENCEAND THE DIABETIC PATIENT \\ ÁREAS DE SILENCIO Y CUERPO DIABÉTICO
}

Maria da Glória Santana'

RESUMO: O texto busca refletir a respeito da experiência vivida pelo ser humano e diabético, ao ter que enfrentar a perda de alguma parte do seu corpo. Fundamentou-se a reflexão em Merleau-Ponty (1971), partindo de sua afirmativa de que o corpo fala e portanto também silencia. Mas que silêncio è esse de que me refiro? Um silèncio simbólico, mais silencioso que o verdadeiro silêncio. Um silêncio forte, pesado e significativo. Um silêncio que atordoa, permanente e eterno. Um silêncio que marca, que lembra e que também se adapta. Um silêncio proveniente da vida e da adaptação a nova forma de viver

PALAVRAS-CHAVE: diabético, corpo, enfermagem

Por que denominei áreas de silêncio a minha reflexão sobre o corpo do ser diabético? Porque pensar que esse corpo silencia quando sei que ele fala. Silencia porque parte do seu corpo que falava já não se encontra mais ali, entretanto, não se encontra ali num contexto fisico, mas se encontra ali no seu imaginário. Num imaginário que é parte do seu cotidiano, parte de toda a sua existência, parte do ser. Como posso esquecer uma parte do meu ser se quando essa mesma parte esteve presente em mim por toda a vida? Quando sei que o corpo que sou e o corpo que tenho faz parte de mim e que, portanto, sou eu? Quando sou consciente de que o meu corpo não é somente o físico, mas é também o meu espírito. Corpo é mais que mente é mais que espirito. Corpo é dinâmica é transformação, é vida, é luz!

Perder parte desse corpo que faz parte de mim é, de certa forma, um ter que se acostumar com este novo ser, na incompletude, mas que pensa um novo modo de ser. $\dot{E}$ aprender a ser e viver sem o meu braço, a minha perna e, assim, compreender-se no novo contexto de vida.

Diabetes também é mutilação, é fazer criar áreas de silêncio no seu corpo, partindo de Merleau-Ponty (1971), quando diz que o corpo fala e, quando falta a esse corpo alguma de suas partes, ali esse corpo silencia.

Muitos diabéticos expressam o medo de ter uma parte do seu corpo mutilada. A prática tem nos mostrado que nem sempre esse ser se encontra preparado para conviver com esse corpo reduzido. Essas situações são vividas, geralmente, de forma emergencial e o preparo, tanto de profissionais, como daqueles que vão ser submetidos a esses tratamentos radicais, carecem de maiores reflexões. Na verdade, informar a alguém sobre uma decisão desse tipo é, no mínimo, doloroso para ambos (profissional e ser diabético). Pois, o corpo representa o homem, nossa presença no mundo, e, também, por esse corpo ter sido e estar cada vez mais sendo valorizado pela sua exterioridade, tornando-se mais importante a sua aparência.

Merleau-Ponty (1971) fala-nos que a recusa do ser humano em aceitar a mutilação e a deficiência justifica-se por ser um eu engajado num certo mundo físico e inter-humano, que continua a se estender em direção a seu mundo, apesar das deficiências ou das amputações

'Doutora da Faculdade de Enfermagem e Obstetricia da Universidade Federal de Pelotas. Mestre em Saúde do Adulto. 
e que, nessa medida, não os reconhece.

O corpo, enquanto presença, no mundo - corporeidade, é capaz de guardar o seu campo prático no trânsito do seu quotidiano antes de uma mutilação. Porém, ele também é capaz de guardar, conscientemente, o espaço do corpo habitual e do corpo atual, como o denomina Merleau-Ponty (1971), ou seja, mesmo tendo seu corpo reduzido numa situação presente, ainda assim permanece a consciência diante do seu corpo inteiro de antes. Assim, surge a ambigüidade, própria do ser que mudou a sua situaçăo de corpo habitual, para corpo real, enquanto presença no mundo a fim de adaptar-se a uma nova situação como ocorre com as pessoas que vivem essa realidade.

É muito comum a relação do ser com sua perna amputada, quando, muitas vezes, é referido como se ela estivesse presente, ocupando esse espaço, no seu mundo atual. É o que chamamos de perna fantasma, quando ele verbaliza que sente coceiras ou cócegas na planta do pé. Muitas vezes, quando não temos consciência da situação, afirmamos que esse ser está desorientado ou fora da realidade. Nesse sentido, "ter uma perna fantasma" parece ser, um permanecer aberto e vulnerável a todas as açōes que só essa perna seria capaz de fazer, ou seja guardar o campo prático que se tinha antes da mutilação.

O que acontece, segundo Merleau-Ponty (1971), é uma atitude ambígua do ser mutilado, nessas regiōes de silêncio: como ele percebia sua perna antes e como ele a percebe agora. Se o meu corpo é o veiculo no mundo, então, a ausência de uma parte do corpo ainda é uma presença na sua comunicação com esse mesmo mundo. Como se dá essa adaptação de algo que fazia o ser presente no mundo por inteiro, e que agora o reduz? Como esse ser se percebe com um corpo incompleto e como é percebido pelos outros? Continua sendo humano? Para que serve se o seu corpo se descompleta?

$\mathrm{Na}$ verdade, sente que continua inteiro como ser no mundo, enquanto homem e singularidade. Continua presente enquanto consciência, razão e afeto. Porque é um corpo e não se tem só um corpo. É sujeito que se sente, chora, e pensa, que, independente de um pedaço que the foi tirado, sua presença no mundo está aqui inteira, viva e vibrante. Assim, para ele, sua qualidade de vida aumenta quando sua consciência pela vida está presente.

Trago ao leitor em forma de poema o meu sentir, sobre o corpo do ser humano e diabético no momento em que produzi esta reflexão.

\author{
Corpo \\ Corpo, \\ Máquina humana \\ Estrutura real e sensivel. \\ Presença no mundo \\ Comunicação com o universo. \\ Corpo que se articula e faz articular-se \\ Entre outros corpos \\ Corpo e ser. \\ Configuraçăo do homem no universo. \\ Corpo que se mostra, \\ Que se vê \\ Que sente. \\ Que sai de si sem se mostrar \\ Corpo que identifica \\ Que é sujeito e subjetividade. \\ Que une, sendo intersubjetividade \\ Nas interfaces de seu vivido. \\ Corpo que vincula, \\ Que age.
}


Que se esparge no mundo.

Corpo

E como sou como me vejo

Como te vejo.

Como sou eu

E vocé.

Somos todos nós.

Corpo não é só identidade

Identidade de si

Mas é um sair de si

E um estar fora de si

Num vai-e-vem que aproxima e se afasta

Nesta dança que é a vida.

Corpo que transcende.

Que luta

Que se debate

Que se adapta

E se fragiliza

Que também se recupera.

Corpo que se move.

Que se multiplicando

Multiplica a vida.

Esse corpo.

Essa vida

Sou eu, estão em mim,

Pulsando.

Vivendo.

Sentindo.

Pensando,

Desejando

E fazendo seguir para longe o seu desejo Quando penso o meu corpo com cérebro. Coraçāo e Instinto

Me sinto com uma Imensidăo de vida

$\mathrm{Se}$ o corpo sou EU

E a minha forma de ser no mundo.

E a prova da minha existência.

Sinto-me maior frente ao mundo.

Ao Meu ser.

Frente ao outro que me rodeia.

Na medida em que penso

$O$ outro na minha volta,

E percebo que ele se completa

E se complementa em Mim

E nos completamos juntos.

Sinto que somos a soma

de Um com o Outro.

Sinto que nos relacionamos numa só nota.

Sinto que

Se faz presente nossa subjetividade.

Nosso entrelaçamento Humano e sensivel. 
ABSTRACT: This text intends to reflect on the experience of diabetics who face the loss of a part of their body. The reflection is based on Merleau-Ponty's idea that the body speaks and therefore it also silences. But what silence is this text referring to? It refers to a symbolic silence, more silent than the real silence, a strong, heavy and meaningful silence. A kind of silence that stuns, that is permanent and eternal. A silence that marks, that reminds and also adapts itself. A silence deriving from life and from the adaptation of a new way of living

KEYWORDS: diabetes, silence

RESUMEN: El texto hace una reflexión sobre la experiencia vivida por el ser humano que está diabético y tiene que afrontar la pérdida de alguna parte de su cuerpo. La reflexión se fundamentó en MerleauPonty, cuando argumenta que el cuerpo habla y, por lo tanto, tambièn silencia. Pero, ¿qué tipo de silencio es ese al que me refiero? Un silencio simbólico, más silencioso todavia que el verdadero silencio. Un silencio fuerte, pesado y significativo. Un silencio que apabulla, permanente y eterno. Un silencio que marca, que recuerda y que también se adapta. Un silencio proveniente de la vida y de la adaptación a la nueva forma de vivir.

PALABRAS CLAVE: diabético, cuerpo, enfermeria

\section{BIBLIOGRAFIA}

BOEMER, M. R. A condução de estudos segundo a metodologia de investigação fenomenológica. Revista Latino Americana de Enfermagem, Ribeirão Preto, v.2, n.1, p.83-84, abr/jun. 1984.

CAPALBO C. Fenomenologia e hermenêutica. Rio de Janeiro: Âmbito Cultural, 1986

DAMASCENO, M. M. C. O ex-sistir do diabético da fenomenologia à enfermagem. Rio de Janeiro, 1996. (Tese de Doutorado) Escola de enfermagem Ana Nery da UFRJ

KANT. Dicionário de Filosofia. São Paulo: Scipione, 1994 1. parte: Metafísica dos Costumes Doutrina do Direito, p. 55

MARTINS, J; FARINHA, M. F. S. Temas fundamentais de fenomenologia. São Paulo: Moraes, 1984.

MERLEAU-PONTY, Maurice. Fenomenologia da percepção. Trad. De R. Piero. São Paulo: Freitas Bastos, 1971. 465p.

REZENDE, Antônio Muniz de Concepção fenomenológica da educaçāo. São Paulo: Cortez/Autores Associados, 1990. (Coleção Polêmica do Nosso Tempo, v.38).

ROGERS, Carl. Tornar-se pessoa. 3.ed. São Paulo: Martins Fontes, 1961

\section{Recebido em outubro de 1999 \\ Aprovado em junho de 2000}

